\title{
Heavy Metals Content in Some Gardening Soils in Makurdi Metropolis
} Oklo, A. $\mathrm{D}^{1^{*}}$, Enenche, D. $\mathrm{E}^{2}$ and Uzungwe, T.

${ }^{1}$ Department of Chemistry, Benue State University Makurdi, Nigeria

${ }^{2}$ Department of Pure and Industrial Chemistry, Nnamdi Azikiwe University, Awka Anambra State

\author{
DOI: $10.36348 /$ sijcms.2021.v04i03.001 \\ | Received: 17.02.2020 | Accepted: 26.02.2020 | Published: 18.03.2021 \\ *Corresponding author: Oklo, A. D
}

\section{Abstract}

Heavy metals have great significance due to their tendency to accumulate in the vital human organs over prolonged period of time. Injury to vegetation caused by heavy metals has been well recognised because of the many botanical and chemical investigations during the past century. The high concentration of heavy metals in the soil is reflected by higher concentration of metals in plants and consequently in animal and human bodies. The analysis of heavy metals in some gardening soils was carried out from soil samples at sites W (Wadata), X (Lower Benue), Y(Tionsha) and Z(Wurukum) using Atomic Absorption Spectrophotometer and the results obtained were in the following ranges Cd $0.001 \pm 0.0002-$ $0.14 \pm 0.001 \mathrm{mg} / \mathrm{kg}, \mathrm{Cu} 0.01 \pm 0.05-0.15 \pm 0.0006 \mathrm{mg} / \mathrm{kg}, \mathrm{Pb} 0.15 \pm 0.01-0.23 \pm 0.005 \mathrm{mg} / \mathrm{kg}$ and $\mathrm{Ni} 0.06 \pm 0.0009-0.10$ $\pm 0.009 \mathrm{mg} / \mathrm{kg}$. The highest concentration of as was at Tionsha, while $\mathrm{Cd}, \mathrm{Cu}, \mathrm{Pd}$ and $\mathrm{Ni}$ was at Wadata, While the least was at Wurukum, Lower Benue and Tionsha respectively. As was found to be Below Detectable Limit (BDL) at Wadata and Lower Benue, $\mathrm{Cu}$ at Tionsha, Pd at Lower Benue and Tionsha and $\mathrm{Ni}$ also at Lower Benue and Tionsha. Generally, the result showed that the values were within the set standard for heavy metals in the soil.

Keywords: Heavy metals, (BDL), soil, vegetation.

Copyright @ 2021: This is an open-access article distributed under the terms of the Creative Commons Attribution license which permits unrestricted use, distribution, and reproduction in any medium for non-commercial use (NonCommercial, or CC-BY-NC) provided the original author and source are credited.

\section{INTRODUCTION}

Heavy metals are chemical elements found in the environment and having a density greater than $5 \mathrm{~g} / \mathrm{dm} 3$; they are regarded as microelements due to their basically low contents in soils and plants with biological value [1]. Unlike organic pollutants, heavy metals occur naturally in the earth crust and are naturally existent in rocks and soils with varying range of concentrations in waters, sediments and plants. However, their hydrogeochemical cycles have been greatly accelerated by man [2].

The high level of increasing industrial waste, domestic waste and refuse disposal and the poor sanitary habit in urban settings has led to increase in heavy metals contamination of soils. Since some of these soils are used as gardening soils, the vegetables grown on them could become a poison to the consumer if the vegetables are contaminated by these metals (since the rate of heavy metals uptake is proportionate to their availability in the soil.

Soil as a component of the environment is very essential for life here on earth. Soil can then be defined 'as the top layer of the earth's crust'. It is formed by mineral particles, organic matter, water, air and living organisms. It is in fact an extremely complex variable and living medium. Soil is a non-renewable resource which performs many vital functions; food and other biomass production, storage, filtration and transformation of many substances including water, carbon and nitrogen. It serves as a platform for human activities and acts as a provider of raw materials [3]. Even though it naturally contains trace elements, at elevated levels this medium becomes contaminated.

The ideal gardening soil is deep fertile, well drained, has plenty of organic matter and is free of weeds and contamination [4]. It can also be said to have a mixture of $20 \%$ clay, $40 \%$ silt and $40 \%$ sand [5]. Though such soils are difficult to find but with proper preparation and management, less than ideal soils can be productive. The gardening soil thus affects the way vegetables grow, which has to do with the soil's physicochemical properties and contamination [4].

The contamination of the soil with heavy metals affects the plants (herein considered as vegetables) grown on such soils. Heavy metals have great significance due to their tendency to accumulate in the vital human organs over prolonged period of 
time. Injury to vegetation caused by heavy metals has been well recognized because of the many botanical and chemical investigations during the past century. Plants are more sensitive to pollution than animals [6]. The high concentration of heavy metals in the soil is reflected by higher concentration of metals in plants and consequently in animal and human bodies [7].

The concentration of heavy metals in the soil plays a critical role in controlling the availability of ions to plants. The solubility and therefore the bioavailability of heavy metal ions vary widely because many factors influence their concentration in soil solution, the most important factors being soil $\mathrm{pH}$, clay content and organic matter. Heavy metal concentrations in the soil are typically quantified and regulated on the basis of total metal content, regardless of their solubility. However, soils containing large amount of colloidal organic and mineral material can sorb and immobilize these metals to a greater extent than soils with low content of these reactive materials [8]. There is therefore need to continuously monitor the heavy metal composition of garden soils.

\section{Sampling Location}

Four locations in Makurdi metropolis of Benue State were sampled which included river bank (wurukum), lower Benue, Tionsha (industrial layout) and Wadata (rice mill). Samples from these selected areas of gardening soils were collected in January 2014, using a sampler and a trowel. The samples were collected using the composite method.

\section{Sample Collection}

Sample were collected at a depth of $10-15 \mathrm{~cm}$ from two spots in each location and mixed. All samples collected were put in different polyethylene bags and labelled appropriately as (W) for Wadata, (X) for Lower Benue, (Y) for Tionsha, and (Z) for Wurukum and the samples were taken to the laboratory for further analysis.

\section{Sample Pre-Treatment}

Stones and extraneous materials were screened from the collected soil samples, and air dried in the laboratory at room temperature for seven days with occasional mixing to expose other areas for proper drying. The samples were crushed and passed through a mesh sieve of $2.0 \mathrm{~mm}$. This is done repeatedly to present very good soil sample for further analysis.

\section{STATISTICAL ANALYSIS}

Data obtained were analyzed using Microsoft Excel and results were expressed as mean \pm standard deviation.

\section{METHODS}

\section{Determination of $\mathrm{pH}$ of the Soil}

$10 \mathrm{~g}$ of the dried soil sample was weighed into a $100 \mathrm{~mL}$ beaker. $25 \mathrm{~mL}$ of distilled water was then added and the resulting suspension was stirred for about 30 min using a spatula. The suspension was allowed to stand undisturbed for another 30 minutes. The $\mathrm{pH}$ electrode was then immersed in the suspension (with care taken not to touch the bottom of the beaker) and the $\mathrm{pH}$ reading noted after about $1 \mathrm{~min}$. The procedure was repeated for all samples taking two readings in each case and taking the mean value [3].

\section{Digestion of Soil Sample}

$0.5 \mathrm{~g}$ of the well mixed air-dried sample was weighed and digested in $12 \mathrm{ml}$ of aqua regia $\left(1: 3 \mathrm{HNO}_{3}\right.$ $\& \mathrm{HCl}$ ) and heated on a gas burner (in a fume cupboard) for about 15 minutes at $110^{\circ} \mathrm{C}$. After evaporation to near dryness, the sample was diluted with $20 \mathrm{~mL}$ of $2 \%\left(\mathrm{v} / \mathrm{v}\right.$ with $\mathrm{H}_{2} \mathrm{O}$ ) nitric acid transferred into a $100 \mathrm{~mL}$ volumetric flask after filtering through Whatman no. 42 filter paper and diluted to $50 \mathrm{~mL}$ with distilled water [9]. The process was done for all samples and blank samples also was prepared in same manner. The samples were assessed for heavy metals using AAS.

\section{Experimental procedure for metals determination}

A serial dilution method was utilized to arrange the working standards and the concentration of the metals in every sample. The concentration was measured by utilizing AAS (Buck Model 210 VGP) outfitted with a computerized readout framework

\section{RESULTS AND DISCUSSION}

As given in Table-1, the heavy metal most readily detected was $\mathrm{Cd}$, and the least detected is $\mathrm{Ni} . \mathrm{Cd}$ ranged from $0.001 \pm 0.0002-0.14 \pm 0.001, \mathrm{Cu} 0.01 \pm 0.05$ $-0.15 \pm 0.0006, \mathrm{~Pb}$ from $0.15 \pm 0.01-0.23 \pm 0.005$, and Ni from $0.06 \pm 0.0009-0.10 \pm 0.009$.

Table-1: Mean values of heavy metal concentration in $\mathbf{m g} / \mathbf{k g}$

\begin{tabular}{|l|l|l|l|l|}
\hline & $\mathrm{Cd}$ & $\mathrm{Cu}$ & $\mathrm{Pb}$ & $\mathrm{Ni}$ \\
\hline $\mathrm{W}$ & $0.14 \pm 0.001$ & $0.15 \pm 0.0006$ & $0.23 \pm 0.005$ & $0.10 \pm 0.009$ \\
\hline $\mathrm{X}$ & $0.001 \pm 0.0002$ & $0.01 \pm 0.05$ & $\mathrm{ND}$ & $\mathrm{ND}$ \\
\hline $\mathrm{Y}$ & $0.02 \pm 0.0008$ & $\mathrm{ND}$ & $0.15 \pm 0.01$ & $\mathrm{ND}$ \\
\hline $\mathrm{Z}$ & $0.11 \pm 0.006$ & $0.10 \pm 0.01$ & $0.19 \pm 0.01$ & $0.06 \pm 0.0009$ \\
\hline
\end{tabular}




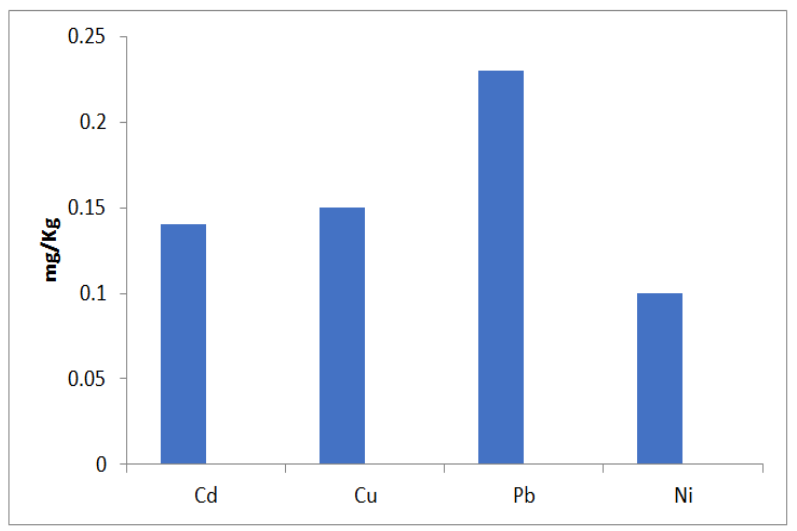

Fig-1: Metal concentrations for Site W (Wadata)

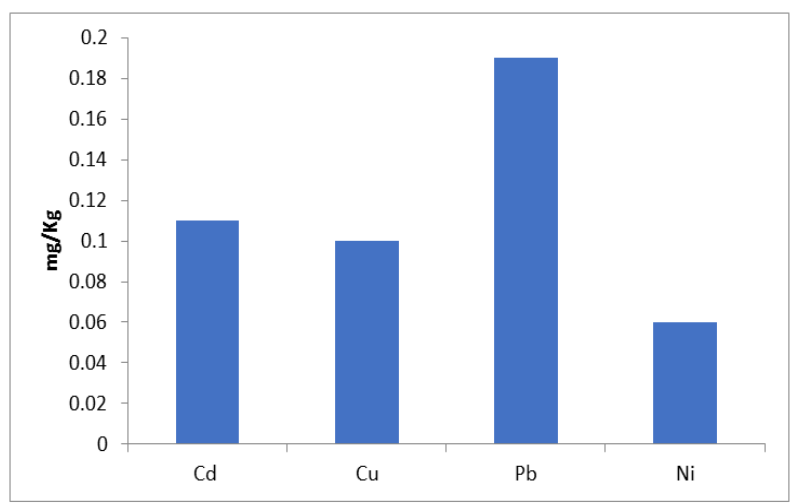

Fig-2: Metal concentrations for Site Z (Wurukum)

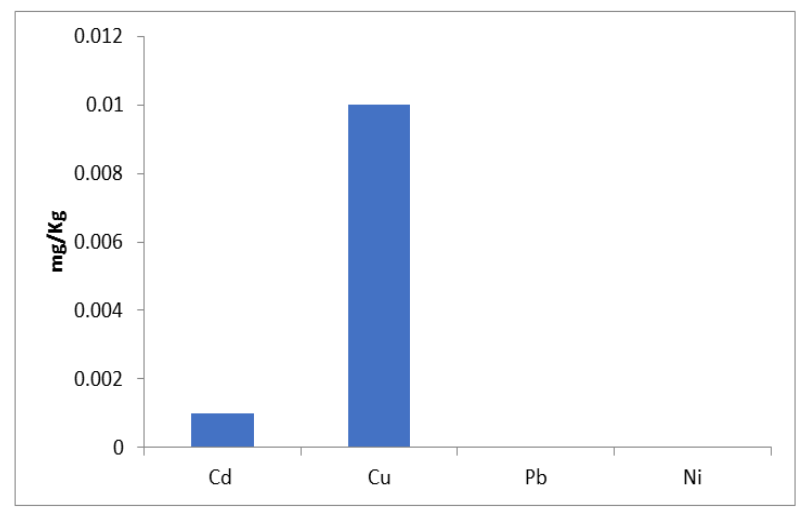

Fig-3: Metal concentrations for Site X (Lower Benue)

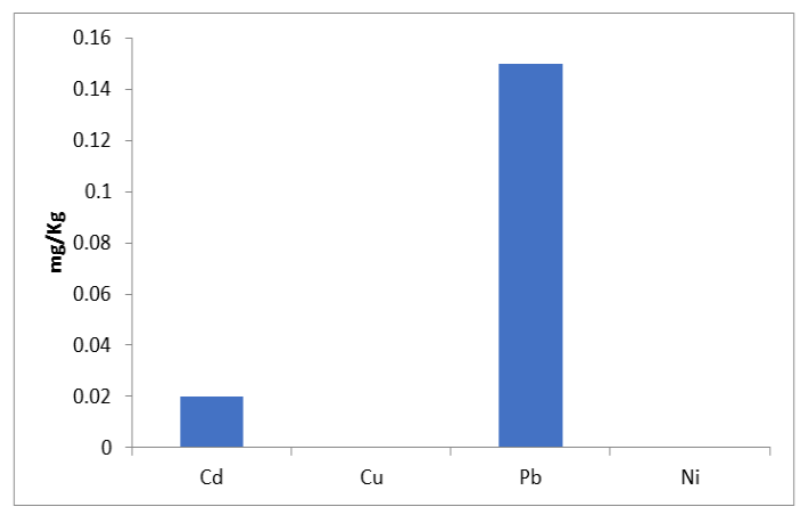

Fig-4: Metal concentrations for Site Y (Tionsha)
At site $\mathrm{W}$ there was higher concentration of $\mathrm{Pb}$ compared to sites $\mathrm{X}, \mathrm{Y}$ and $\mathrm{Z}$ as seen in Figure 1. This may be due to refuse disposal, nearby market, incineration, poor sanitary activities, rice milling activities as well as its ancient history of earlier commercial activities. The contamination trend follows in the other, $\mathrm{Pb}>\mathrm{Cu}>\mathrm{Cd}>\mathrm{Ni}$. $\mathrm{Cd}$ was also found to be highest at this site (Wadata) compared to site X, Y and $Z$. This may also due to dumping activities, rice milling processes and other anthropogenic activities. Its least is at site $\mathrm{X}$ which may be due to absence or significantly small amount of $\mathrm{Cd}$ containing materials.

The highest amount of $\mathrm{Cu}$ was also found at site $\mathrm{W}$ compared to site $\mathrm{X}$ and $\mathrm{Z}$, may be due to the aforementioned reasons. The site $\mathrm{W}$ has highest amount of $\mathrm{Pb}, \mathrm{Cd}, \mathrm{Cu}$ and $\mathrm{Ni}$ than any other site may be due to the aforementioned reasons.

The contamination of the site $\mathrm{W}$ with $\mathrm{Pb}, \mathrm{Cd}$ and $\mathrm{Cu}$ at $0.23 \pm 0.005,0.14 \pm 0.001$ and $0.15 \pm 0.0006$ differs only a little with similar results obtained by Anhwange, et al. (2012) which is $0.19 \pm 0.01,0.13$ \pm 0.09 and $0.12 \pm 0.05$ respectively, thus, showing that there is a slight increase in contamination of the soil by $0.04,0.01$ and 0.03 respectively. The result also compared to work by Idoko [9], which showed increase in $\mathrm{Pb}, \mathrm{Cd}$ and $\mathrm{Cu}$. Similarly, site $\mathrm{Z}$ experiences a similar trend compared to the work by Anhwange et al., [3] and Idoko [9].

Given in Figure-2, Site X (the control site) shows relatively low concentration of all the heavy metals which may be due to least disposal of industrial, market and agricultural waste as well as vehicular emissions which serve as standard for the other sites that are not wholly residential. Though $\mathrm{Cu}$ shows a comparatively high concentration. On the other hand, $\mathrm{Pb}$, and $\mathrm{Ni}$ are least at site $\mathrm{X}$ which may be due to the residential nature of the site as well as less traffic activities and industrial disposal.

From Figure-3, it is seen that site $\mathrm{Y}$ also has very low concentration of heavy metals because the point of collection was rather residential than industrial, therefore the concentration of heavy metals is not expected to be high. $\mathrm{Cu}$ and $\mathrm{Ni}$ were not detected at site $\mathrm{Y}$ may be due to significantly low disposal of refuse at the collection site. Though $\mathrm{Pb}$ and $\mathrm{Cd}$ are detected but at low rates

Site $\mathrm{Z}$ shows presence of all heavy metals analysed as given in Figure-4. This may be due to effluents from the river, market refuse, abattoir activities as well as traffic emissions. Site $\mathrm{Z}$ has concentrations in the range $\mathrm{Pb}>\mathrm{Cd}>\mathrm{Cu}>\mathrm{Ni}$ but the mean values are slightly less than those in site $\mathrm{W}$. 


\section{CONCLUSION}

The garden soils from Makurdi metropolis recorded significant levels of heavy metals, especially at site $\mathrm{W}$ and $\mathrm{Z}$. The results showed that all the four heavy metals $(\mathrm{Cd}, \mathrm{Cu}, \mathrm{Pb}$ and $\mathrm{Ni})$ analysed were present in soil samples from site $\mathrm{W}$ and $\mathrm{Z}$. Site $\mathrm{X}$ contained $\mathrm{Cd}$ and $\mathrm{Cu}$ while site $\mathrm{Y}$ had $\mathrm{Cd}$ and $\mathrm{Pb}$ present. However, the metals were below the permissible limits for soils. The contamination of the environment with heavy metals pose hazard to human and animal health, through bioaccumulation and biomagnification in plants grown in the area. The need for periodic monitoring of toxic metals in this area is crucial to protect human health and the environment.

\section{REFERENCES}

1. Oguntimehin, I., \& Ipinmoroti, K. (2008). Profile of Heavy Metals from Automobile Workshops in Akure, Nigeria. Journal of Environmental Science Technology, 1(1), 19-26.

2. Pam, A. A., Sha'Ato, R., \& Offem, J. O. (2013). Contributions of Automobile Mechanic Sites to Heavy Metals in Soil: A Case Study of North Bank Mechanic Village Makurdi, Benue State, Central Nigeria. Journal of Chemical, Biological and Physical Sciences, 3(3), 23372347.
3. Anhwange, B. A., Agbaji, E. B., \& Gimba, E. C. (2012). Assessment of top soil of Some Selected areas within Makurdi Metropolis. Scholars Research Library. Archives of Applied Science Research 4(4):1591.

4. Essington, M. E. (2004). Soil and Water Chemistry; An interactive approach. London, Bocapracton cpc press. 6-8

5. Greenland, D. J., \& Hayes, M. (1981). The Chemistry of soil Processes. New York, Willey interscience publication. 593.

6. Yousuzai, A.H.K. (2006): Determination of Heavy Metals in Vegetables and Soils at Sewage Farm in Sindh industrial Trading Estate. Karachi.

7. Delbari, A. S., \& Kulkarni, D. K. (2000). Determination of Heavy Metal Pollution in Vegetable grown along the roadside Tehran-Iran. Scholar Research Library Journal.

8. Mitsios, I. K. Golia, E. E., \& Tsadilas, C. D. (2001). Heavy Metal Concentration in Soils and Irrigation Waters in Thessaly region, Central Greece.

9. Idoko, J. A. (2008). Determination of the Concentration of heavy Metals in Irrigated Farms, along the Bank of River Benue in Makurdi. A project work submitted to the Department of Chemistry, Benue State University, Makurdi, 25. 